\title{
Bioremediation of palm industry wastes using vermicomposting technology: its environmental application as green fertilizer
}

\author{
Parveen Fatemeh Rupani ${ }^{1}$ - Asha Embrandiri ${ }^{1}$ - Mahamd Hakimi Ibrahim ${ }^{1}$ • \\ Mohammad Shahadat $^{2} \cdot$ Sune Balle Hansen ${ }^{3} \cdot$ Nur Naha Abu Mansor ${ }^{4}$
}

Received: 12 November 2016/Accepted: 6 February 2017/Published online: 16 June 2017

(c) Springer-Verlag Berlin Heidelberg 2017

\begin{abstract}
Several technologies are being applied for treatment of palm oil mill wastes. Among them, the biological treatments (vermicomposting) have widely been recognized as one of the most efficient and eco-friendly methods for converting organic waste materials into valuable products. The present study focuses on vermicomposting of acidic palm oil mill effluent (POME) mixed with the palm pressed fibre (PPF) which are found difficult to decompose in the environment. The industrial waste (POME) was vermicomposted using Lumbricus rubellus under laboratory conditions for a period of 45 days. A significant improvement in nitrogen, phosphorus, and potassium content was monitored during vermicomposting process. In addition, the decline in $\mathrm{C}: \mathrm{N}$ ratio of vermicompost (up to $17.20 \pm 0.60$ ) reflects the degree of stabilization of POME-PPF mixture. Different percentages of the vermicompost extract obtained from POME-PPF mixture were also examined for the germination of mung bean (Vigna radiata) seed. The results showed that $75 \%$ vermicompost extract demonstrated better performance for the seed germination. On the basis of significant findings, POME-PPF mixture can be successfully used as a feeding
\end{abstract}

Parveen Fatemeh Rupani

pfr09_tec090@student.usm.my

1 School of Industrial Technology, University Sains Malaysia, 11800 Penang, Malaysia

2 Department of Biochemical Engineering and Biotechnology, Indian Institute of Technology, Delhi, New Delhi 110016, India

3 Palm Oil Research Centre, Universiti Teknologi Malaysia, 54100 Kuala Lumpur, Malaysia

4 Faculty of Management, Universiti Teknologi Malaysia, 81310 Johor Bharu, Malaysia material for the earthworms, while on the other hand, it can also be used as a cost-effective fertilizer for the germination and the proper growth of mung bean.

Keywords Palm oil mill effluent - Palm pressed Fibre . Earthworms · Vermicomposting - Seed germination . Environmental applications

\section{Introduction}

The production of crude palm oil in Malaysia has increased and reached approximately $40 \%$ in improvement as compared to the past decade (4.0 million tonnes in 2004 and standing at a peak value of 19.2 million tonnes by 2013 (MPOB 2014). As per the global index, more than one-third of vegetable oil production is achieved by the processing of oil palm fruit together with other wastes including palm oil mill effluent (POME), empty fruit bunches (EFB), palm pressed fibre (PPF), as well as palm kernel shell (PKS) (Madaki and Seng 2013). In addition to it, disposal of these wastes without any proper treatment causes harmful impacts to the environment (Hansen et al. 2012). It is also found that POME contains high organic content $(80,000 \mathrm{mg} / \mathrm{L}$ COD) (Abdurahman et al. 2011) along with water soluble and suspended materials (palm fibre and oil residues). Before the implementation of stringent environmental protection criteria (in the past 1960), POME either partially treated or as a raw material was directly discharged into the water bodies (Okwute and Isu 2007) which resulted in the devastating of eutrophication. For the treatment of POME, anaerobic and facultative treatment process in open lagoons was also introduced in the 1970s. The research of Lam and Lee (2011), however, proved how this treatment caused the emissions of greenhouse gases (e.g., $\mathrm{CH}_{4}, \mathrm{NO}_{2}$, etc.). To

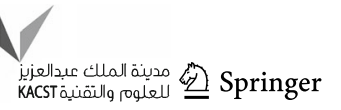


minimize the adverse effect, these residues can be recycled using biological treatment (Hansen et al. 2012). Therefore, attention has been paid to recycle as well as utilize the organic content of POME residues using biological processes (composting of palm oil mill waste) (Salètes et al. 2004; Baharuddin et al. 2010). Thus, in the process of composting, the organic wastes are transformed into a more stable material by the successive activities of different microbes which are effectively used in agriculture. To achieve higher productivity, a rapid composting system is required. Therefore, a co-composting method was proposed by the composting of lignocellulosic solid wastes mixed with POME for the time duration of 60-90 days (Baharaddin et al. 2009; Yahya et al. 2010; Krishnan et al. 2016). The composting of palm oil waste suffered from some drawbacks including long-time duration, regular requirement of aeration, and loss of nutrients (nitrogen off-gassing). To remove all the drawbacks associated with the traditional composting process, the management of POME was carried out using one of the green techniques of vermicomposting which is widely recognized as one of the most efficient eco-friendly methods for converting organic waste materials to valuable products (Mathur et al. 2006). Vermicomposting is a commercial and rapid biological waste treatment technology, which enhances the nutrient stabilization through a non-thermophilic process (Molina et al. 2013). In this process, organic waste material is simply digested biologically and converted into earth-like, soil-building substances (Edwards and Bohlen 1996). However, the low $\mathrm{pH}$ of substrate makes the vermicomposting process unsuitable for the growth of epigeic earthworms. Consecutively to utilize POME by vermicomposting, a bulking material is mixed with POME. Palm pressed fibre (PPF) was chosen as bulking material to utilize another oil palm industry same waste. On the other hand, PPF has good soil conditioner efficiency and it could be used as an animal feed. Macci et al. (2009) reported vermicomposting of lingocellulosic material; PPF mixed with acidic olive oil to produce a suitable environment for earthworm growth. Up to date, no work related to the recycle of acidic POME mixed with PPF was carried out using the vermicomposting process. Hence, the present work deals with the management of the POME-PPF mixture using vermicomposting and its environmental application as a green fertilizer for the evaluation of earthworm growth.

\section{Materials and methods}

\section{Materials}

Fresh POME and PPF were obtained from the MALPOM industry Sdn. Bhd, Nibong Tebal, Malaysia. Different age groups of earthworms belonging to L. rubellus species were obtained from a vermiculture unit in Penang, Malaysia. The stock culture of the earthworm was maintained in plastic containers using partially decomposed mixture of bio-waste as a growth medium under laboratory conditions $\left(26 \pm 2{ }^{\circ} \mathrm{C}\right)$ for further use during the vermicomposting. In the present study, a slight modification in vermireactor was made as compared to reported vermireactor (Gajalakshmi et al. 2005; Jain et al. 2003), in which pebbles were used as a bedding material in place of cloth to facilitate good drainage.

\section{Design of experiment for vermicomposting using POME-PPF mixture (1:1 ratio)}

The POME-PPF mixture and earthworms were placed in a plastic container $(24 \times 24 \times 24 \mathrm{~cm})$ over the pebble layer. A fixed amount of feed material, POME-PPF mixture (1.0 kg each fresh POME and PPF in 1:1 ratio on the basis of wet weight), was introduced at the beginning of experiment and the mixture was pre-composted for 15 days to improve its palatable quality for the earthworms (Deka et al. 2011a; Sangwan et al. 2008). Each experiment runs in triplicate with three vermireactors as well as three control reactors (without earthworms). After 15 days, a fixed number of earthworms (20 earthworms, each contain $5.03 \mathrm{~g}$ weight) were individually introduced in each reactor (Adi and Noor 2009). Thereafter, all vermireactors were kept under the laboratory condition and daily sprinkled with water to keep the mixture moist $\left(26 \pm 2{ }^{\circ} \mathrm{C}\right)$. Each experiment was terminated at the end of 45 days (30 days of vermicomposting). After 45 days, the earthworms were separated by hand-sorting method from each container, and washed with tap water to remove any adhering material from their body which was subsequently counted and weighed. The weighed earthworms were returned to their respective reactors. A fixed amount $(50 \mathrm{~g})$ of homogenized vermicompost sample (free from earthworms, hatchlings, and cocoons) was collected from each reactor at every interval of 10 days. The samples were oven dried $\left(100{ }^{\circ} \mathrm{C}\right)$, ground, and stored in labelled plastic bags for further analysis using recommended standard methods. The temperature of compost was then monitored using thermometer following the APHA (1992) method. The $\mathrm{pH}$ of vermicompost determined using a doubled distilled water suspension in the ratio of $1: 10(\mathrm{v} / \mathrm{w})$ by $\mathrm{pH}$ meter. The amount of total organic carbon (TOC) and total nitrogen (N) were measured by $\mathrm{CHN}$ analyser (Shimadzu Model 2400; Benner et al. 1992), while the total phosphorus (P) content was analysed using ammonium molybdate method (Bansal and Kapoor 2000). The total amount of potassium $(\mathrm{K})$ was determined after digesting the sample in a tri-acids mixture $\left(\mathrm{HNO}_{3}+\mathrm{H}_{2} \mathrm{SO}_{4}+\mathrm{HClO}_{4}\right)$ by flame photometer (Simard 1993). The statistical methods; 
ANOVA and Post-hoc Tukey's test were later employed at the significant level of $5 \%(P<0.05)$ using PSAW statistical software (version 18).

\section{The effect of vermicompost extract on plant growth}

The study was performed using POME-PPF vermicompost extracts. The experiments were carried out in sterilized petri dishes (10 cm diameter) lined with Whatman Number 4 filter paper at ambient laboratory temperature (Ogunwenmo 2010). To obtain vermicompost extract, a fixed mass of (50 g) vermicompost obtained from the mixture (at day 45) was soaked in $100 \mathrm{~mL}$ distilled water for $24 \mathrm{~h}$. The resulting extract was filtered through a Whatman No. 4 filter paper and it was used as $100 \%$ vermicompost extract (Zaller 2006). Diluted extracts $(25,50$, and 75\%) were prepared by mixing $100 \%$ vermicompost extract with distilled water in appropriate proportions (v/v). In 0\% sample, only the distilled water was used which acted as a blank or control in the experiment. Thus, the extracts were used to evaluate germination of 15 seeds of Mung bean (Vigna radiate) in each petri dish. The root and shoot length of Mung bean were recorded at every interval of $24 \mathrm{~h}$ (Dhanam 2009).

\section{Results and discussion}

\section{Physico-chemical properties of POME-PPF}

Fresh POME showed acidic nature ( $\mathrm{pH}$ 3.9) with $95 \%$ moisture, whereas PPF has $20 \%$ moisture and covers a $\mathrm{pH}$ value of 5.9. The mixing of POME with PPF increases the $\mathrm{pH}$ of POME-PPF mixture and thus making it a suitable feed for the growth of earthworm. In addition, owing to the high cellulose $(21.3 \%)$, hemicellulose $(31.9 \%)$, and lignin $(26.9 \%)$ content of PPF, it acts as a suitable bulking agent in the vermicomposting process (Lim et al. 2009). The POME also contains nutrients in the form of $\mathrm{N}(23 \%)$, $\mathrm{P}(1.3 \%)$, and $\mathrm{K}(2 \%)$ which make it a suitable condition for the earthworm growth (Rupani et al. 2010). The chemical properties of POME were also found similar to that of olive oil mill wastewater which contains an enormous amount of organic matter $(\mathrm{N}=0.15 \%, \mathrm{P}=0.089 \%$, $\mathrm{K}=0.52 \%$ ). The olive oil wastewater, in this sense, was successfully used for the vermicomposting process (Macci et al. 2009; Mekki et al. 2013).

\section{The effect of $\mathrm{pH}$}

The alteration of $\mathrm{pH}$ in control and vermicompost mixture of POME-PPF (1:1 ratio) during 45 days of vermicomposting is shown in Fig. 1. Herein, the ANOVA followed by Tukey's test did not show any significant difference between 25 th and 45th day in control, while other days showed a significant difference. However, except 25th, 35 th, and 45th day, no significant difference was observed in vermicompost reactor. Moreover, Student's $t$ test between the control and vermicompost of POME-PPF mixture was performed. The results of Student's $t$ test confirmed that $\mathrm{pH}$ did not change significantly from day 0 up to 15 at $5 \%$ level, while it showed significant differences between control and vermicompost in $25 \mathrm{th}, 35 \mathrm{th}$, and 45 th days at $0.1 \%$ level. The absence of significant differences of $\mathrm{pH}$ change among 25, 35, and 45 days in vermicompost verified the gradual stabilization of the ions. It may be attributed to the presence of earthworms which probably stabilizes the mixture. However, the decline in vermicompost $\mathrm{pH}$ after 25 days is found due to the decomposition of organic matter or production of carbon dioxide during the vermicomposting (Suthar 2009; Yadav et al. 2010).

\section{Determination of chemical parameters in control and vermicompost mixture during 45 days (1:1 POME-PPF)}

The chemical parameters, namely total organic carbon (TOC), total nitrogen $(\mathrm{N})$, total phosphorus $(\mathrm{P})$, and total potassium $(\mathrm{K})$, which can also be used as the essential elements in plant nutrition, were studied to observe the chemical changes during vermicomposting process. The percentage of TOC in control and vermicompost reactor of the POME-PPF mixture is shown in Fig. 2a. The obtained results indicate that no changes in the TOC were observed up to 15 days of pre-composting. However, the percentage of TOC was simultaneously decreased at the end of the vermicomposting process. Reduction in TOC might be due to the activity of earthworms in the vermireactors as well as stimulation of microbial metabolism in the gut of

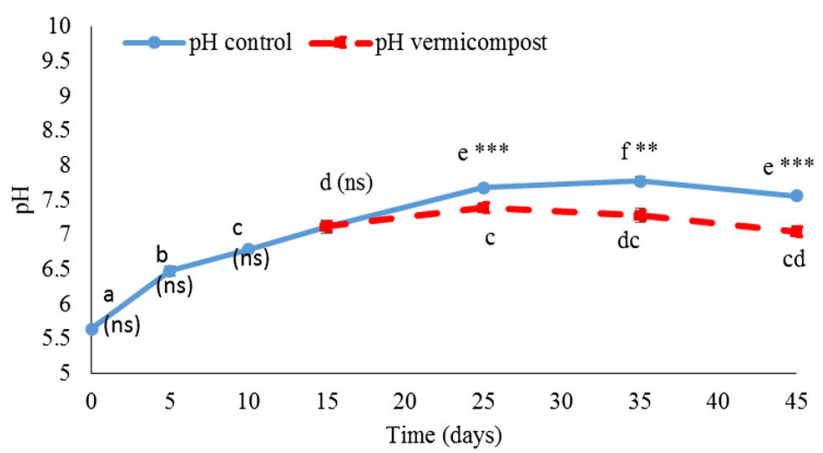

Fig. 1 Changes in $\mathrm{pH}$ during the vermicomposting process of 1:1 ratio of POME-PPF (different letters in each treatment show significant differences at $P<0.05$ ). Day 15 is the time of introducing the earthworm 
earthworms that causes mineralization and transformation of complex carbon compounds into the simplest form. Figure $2 \mathrm{~b}$ explains the percentage of $\mathrm{N}$ in control and vermicompost reactor, which indicates that the total nitrogen content significantly increased $(P<0.05)$ in both control and vermicompost till the end of vermicomposting process. The amount of nitrogen $(1.76 \pm 0.07)$ in vermicompost was found higher than the control one $(1.32 \pm 1.39)$. The enhancement in nitrogen content in vermicompost could also be accredited to the action of earthworms which might be due to the incorporation of mucus and nitrogenous excretory substances from the earthworms (Tripathi and Bhardwaj 2004; Kaushik and Garg 2003; Nogales et al. 2008; Macci et al. 2009). The percentage of phosphorous content in control and vermicompost reactor of POME-PPF mixture (1:1) during 45 days is shown in Fig. 2c. The concentration of phosphorus significantly increased $(P<0.05)$ in both control and vermicompost. Yadav and Garg (2009) also observed an enhancement in the phosphorus content in food industry sludge after vermicomposting. It may be due to the releases of phosphorus from the gut of earthworm which exists in the form of an organic matter in the vermicompost (Lee 1992). The percentage of potassium (K) in control and (a)

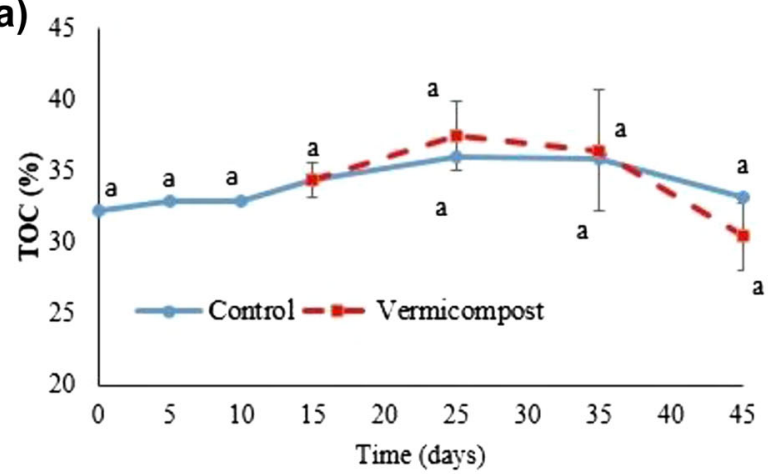

(c)

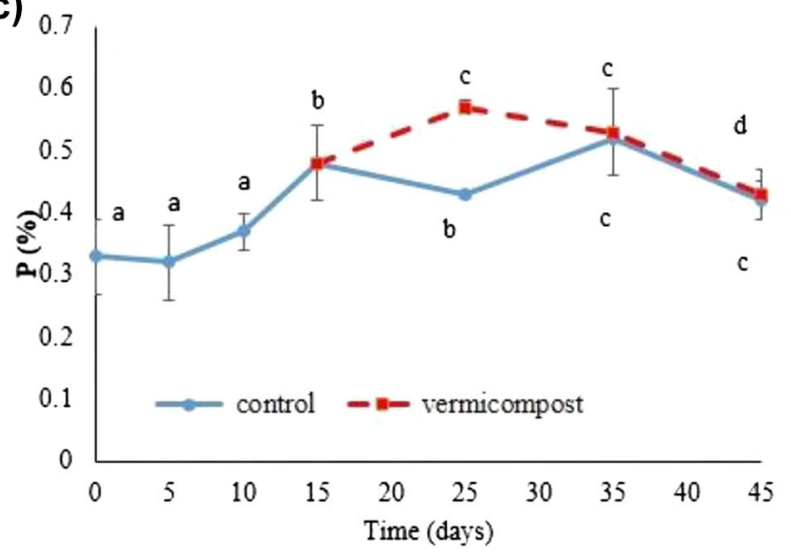

(b) 2.

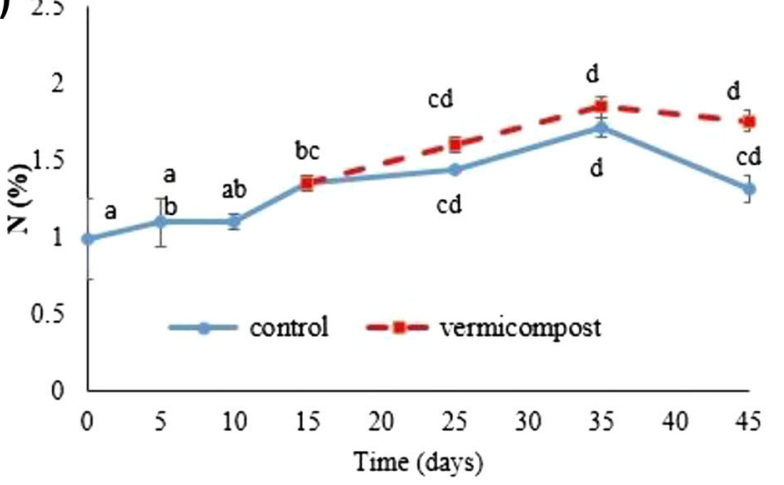

(d)

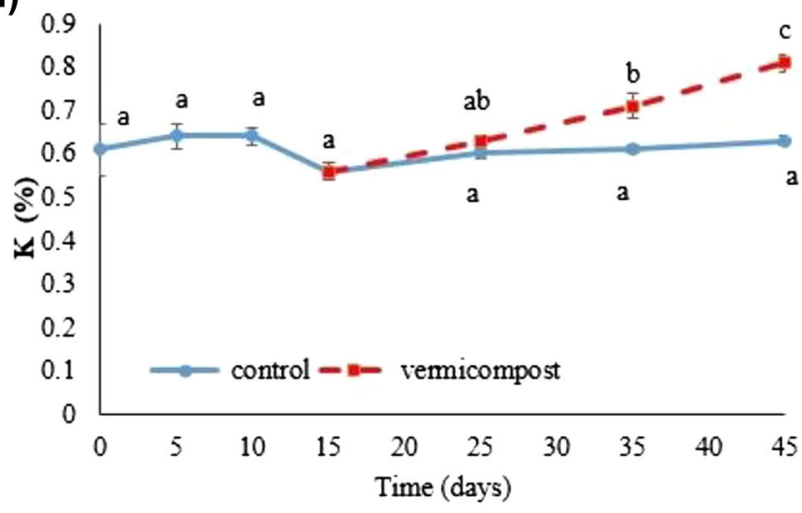

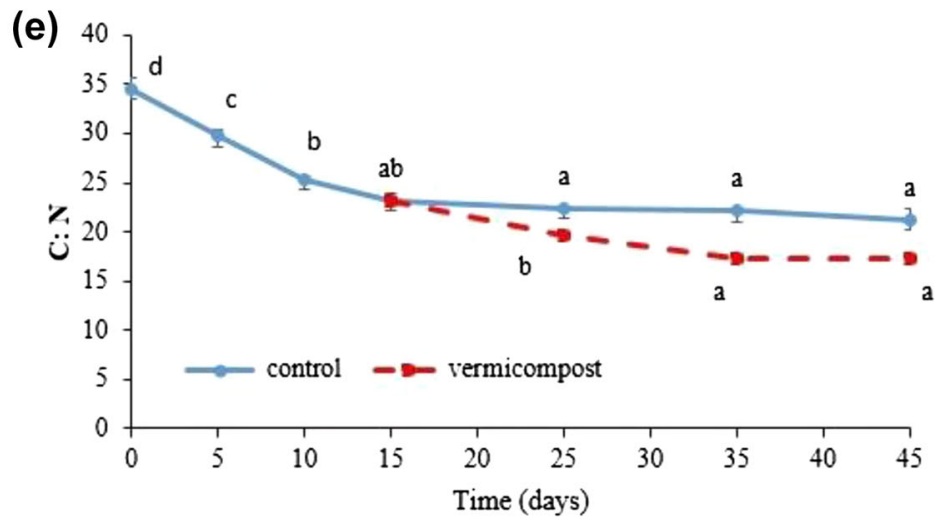

Fig. 2 Changes in the \% of chemical parameters: TOC (a), N (b), P (c), K (d), and C:N (e) in the mixture of POME-PPF (1:1) during the vermicomposting (different letters in each treatment show significant differences at $P<0.05$ ). Day 15 is the time of introducing the earthworm 
vermicompost reactor is shown in Fig. 2d. The amount of $\mathrm{K}$ significantly increased in both compost and vermicompost. The ANOVA for K content followed by Tukey's test during the vermicomposting did not show any significant difference $(P>0.05)$, while it showed a significant difference on the 45th day. Similar finding was also observed by Raphael and Velmourougane (2011) who reported the increment in $\mathrm{K}$ content during the vermicomposting of coffee pulp which might be due to microbial and enzyme activity in the gut earthworm caused higher mineralization. The change in C:N ratio of POME-PPF (1:1) in control and vermicompost reactor during the vermicomposting is shown in Fig. 2e. Initially, the $\mathrm{C}: \mathrm{N}$ ratio of the mixture was $34.51 \pm 1.25$ which decreased to $21.26 \pm 1.18$ in the control and $17.20 \pm 0.60$ in vermicompost, respectively. Herein, the ANOVA for $\mathrm{C}: \mathrm{N}$ shows significant difference $(P<0.05)$ in control and vermicompost. The loss of carbon in the form of $\mathrm{CO}_{2}$ during respiration and the production of mucus as well as nitrogenous excreta enhances the level of nitrogen, which resulted in lower $C: N$ ratio (Senapati et al. 1980). Thus, the decline in $\mathrm{C}: \mathrm{N}$ ratio indicates the maturity of organic composts. The $\mathrm{C}: \mathrm{N}$ ratio below 20 proves an advanced degree of stabilization (Satisha and Devarajan 2007). Furthermore, the lower C:N ratio (less than 15) is more preferable for agronomic use of vermicompost (Morais and Queda 2003). In this experiment, the final $\mathrm{C}: \mathrm{N}$ ratio was found to be in an acceptable range $(17.20 \pm 0.60)$, which indicates a high degree of organic matter stabilization and agronomic potentiality. The present result was also found comparable to the findings of Lim Siong et al. (2009) who reported decline in $\mathrm{C}: \mathrm{N}$ during co-composting of oil palm fibre and palm oil mill effluent.

\section{Environmental applications}

\section{As a natural feed for the growth of earthworm}

Lumbricus rubellus is found in moist organic substrates; animal manure, and sewage solids (Elvira et al. 1997). Usually, animal slurry is cited by Garg and Kaushik (2005), Aira and Domínguez (2008) as the most favourable material for feeding of earthworms. This material is widely used as a medium when earthworms are used as an ecoindicator to investigate environmental or chemical impacts of different soils (Dominguez and Edwards 1997). Furthermore, by-products from crop harvesting such as vineyard waste (Nogales et al. 2005), potato waste (Dominguez et al. 2001), and fruit and grass clippings (Dominguez et al. 2001) are acceptable feed materials for earthworms. However, to produce good vermicompost, these materials should be mixed with other materials which are known to be worm-favourable feeds before being used for vermicomposting (Garg and Kaushik 2005; Sangwan et al. 2008). However, there are many other OSW materials which cannot be directly used as feed for earthworms because of the presence of some toxic chemicals in their components (Kaplan et al. 1980). The toxic factors in feed can be inorganic salts, ammonium, ammonia, alkali, acids, alcohol, methane gas, etc. (Dominguez and Edwards 2004; Edwards 2007; Macci et al. 2009). The examples of acidic substrates are anaerobic digestion wastes (Elvira et al. 1998; Garg and Kaushik 2005; Kuroda et al. 2013), digested solids of biogas slurry (Garg et al. 2006), wastewater from olive oil mill industry (Macci et al. 2009), and effluent from palm oil mill industry. Therefore, organic waste materials have to be pre-treated before being used as a feed for earthworms. In this study, the growth of earthworm biomass (L. rubellus) was examined using mixture of POME-PPF during vermicomposting process. The earthworms with the initial weight of $5.03 \pm 0.26 \mathrm{~g}$ were introduced into the POME-PPF mixture on 15th day of pre-composting process. The data underline that the earthworm biomass significantly increased $(P<0.05)$ by the end of the vermicomposting process (Fig. 3a) that confirms the suitability of the mixture for the growth of earthworms. The growth rate of earthworm with respect to time (in days) is shown in Fig. 3b which revealed that earthworms demonstrate exponential growth from day 35-45 during the vermicomposting of POME-PPF mixture. The increment in the earthworm biomass was also observed by Deka et al. (2011b) and revealed that earthworm growth is an integrated and important aspect of vermicomposting technique.

As a green fertilizer for the seed germination of mung bean

Apart from the earthworm growth, the study on the seed germination of mung bean (Vigna radiata) was also examined using different dilutions $(0,25,50,75$, and $100 \%$ ) of the POME-PPF vermicompost extract. The results of seed germination study showed that in the presence of different dilutions of vermicompost extracts, the enhancement in the shoot length was found higher as compared to the control one (distilled water). The growth in the length of shoot was achieved due to the existence of nutrients in the POME-PPF extract (Fig. 4). Among all dilutions extracts, $75 \%$ of the POME-PPF vermicompost extract demonstrated the highest performance. This confirms that $50 \%$ mixture of the POME-PPF requires less dilution to be used for plants. Arancon et al. (2008) successfully studied the effect of different concentrations of vermicompost extract $(100,10,5$, and $1 \%)$ on the plant growth of tomato (Solanum lycopersicum) and lettuce seeds (Lactuca sativa) with distilled water. The authors concluded that the seedling growth of tomato and lettuce 
(a)

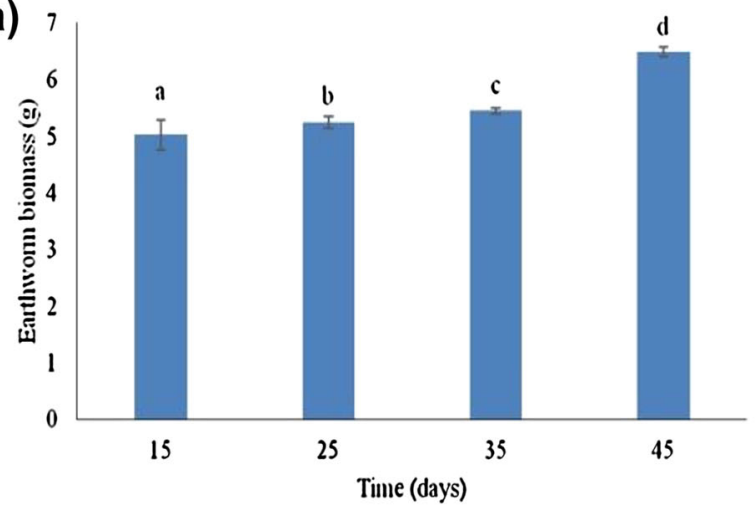

(b)

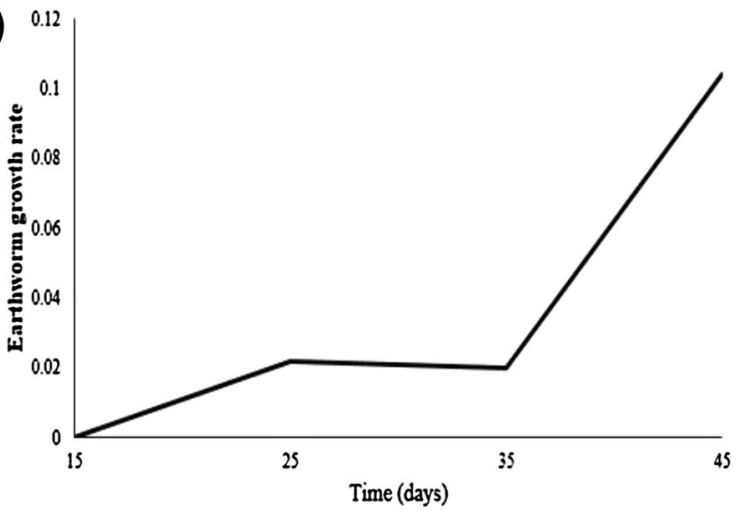

Fig. 3 Earthworm biomass (Lumbricus rubellus) through the vermicomposting process (a), earthworm growth rate (b). Day 15: introduction of earthworms. ANOVA followed by Post-hoc test (Tukey's test) performed, and different letters show significant differences at $P<0.05$

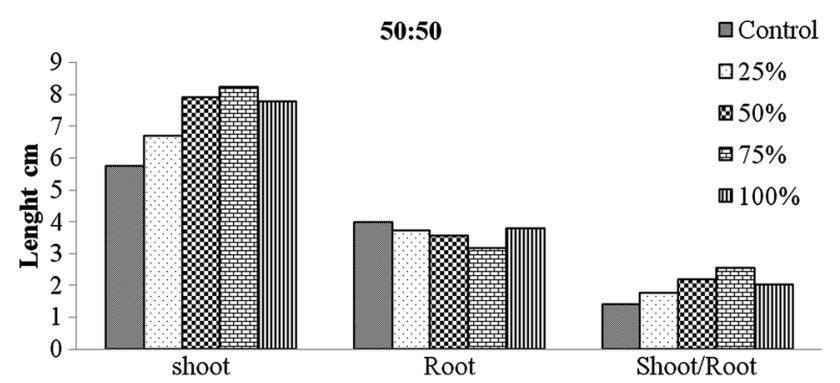

Fig. 4 Effect of different dilutions of vermicomposted POME-PPF extract on the root, shoot length of mung bean

significantly increased $(P<0.0001)$ using vermicompost extract as compared to the control one.

\section{Conclusion}

The transformation of POME-PPF mixture into valueadded products (vermicompost and growth of earthworm) confirmed the utilization of palm industry wastes using vermicomposting technology. The $\mathrm{C}: \mathrm{N}$ ratio below 20 reflects a significant degree of stabilization. The results of seed germination study showed that the lower dilution of vermicompost extract $(75 \%)$ finally resulted in the enhancement of the shoot length of the mung bean plant as compared to the control one (distilled water). Thus, the disposal of POME can be effectively carried out in a controlled way without any chemical treatment as well as no production of environmental pollutants. The present study has potential to contribute to the knowledge bank on residue use in the palm oil industry and it can act as an incentive for further research towards the use of green, economic, and simple technique of vermicomposting in the palm oil industry. On the basis of significant findings, the vermicomposting extract of POME can be effectively and eco-friendly used as a green fertilizer.
Acknowledgements The authors acknowledge USM for providing research facilities funded through Universiti Sains Malaysia (USM) short-term grant number 1001/PTEKIND/81124.

\section{Compliance with ethical standards}

Conflict of interest We hereby declare that there has not been any conflict of interest at any point of time during the preparation of this manuscript.

\section{References}

Abdurahman N, Rosli Y, Azhari N (2011) Development of a membrane anaerobic system (MAS) for palm oil mill effluent (POME) treatment. Desalination 266(1):208-212

Adi A, Noor Z (2009) Waste recycling: utilization of coffee grounds and kitchen waste in vermicomposting. Biores Technol 100(2):1027-1030

Aira M, Domínguez J (2008) Optimizing vermicomposting of animal wastes: effects of rate of manure application on carbon loss and microbial stabilization. J Environ Manage 88(4):1525-1529

APHA (1992) Standard methods for the determination of water and wastewater, 18th edn. American Public Health Association, Washington

Arancon NQ, Edwards CA, Babenko A, Cannon J, Galvis P, Metzger JD (2008) Influences of vermicomposts, produced by earthworms and microorganisms from cattle manure, food waste and paper waste, on the germination, growth and flowering of petunias in the greenhouse. Appl Soil Ecol 39(1):91-99

Baharaddin AS, Wakisaka M, Shirai Y, Abd-Aziz S, Rahman AA, Hassan MA (2009) Co-composting of empty fruit bunches and partially treated palm oil mill effluents in pilot scale. Int J Agric Res 4(2):69-78

Baharuddin AS, Hock LS, Yusof M, Rahman NAA, Shah U, Hassan MA, Wakisaka M, Sakai K, Shirai Y (2010) Effects of palm oil mill effluent (POME) anaerobic sludge from $500 \mathrm{~m} 3$ of closed anaerobic methane digested tank on pressed-shredded empty fruit bunch (EFB) composting process. Afr J Biotech 9(16):2427-2436

Bansal S, Kapoor K (2000) Vermicomposting of crop residues and cattle dung with Eisenia foetida. Biores Technol 73(2):95-98

Benner R, Pakulski JD, McCarthy M, Hedges JI, Hatcher PG (1992) Bulk chemical characteristics of dissolved organic matter in the ocean. Science 255(5051):1561-1564 
Deka H, Deka S, Baruah C, Das J, Hoque S, Sarma H, Sarma N (2011a) Vermicomposting potentiality of Perionyx excavatus for recycling of waste biomass of java citronella-an aromatic oil yielding plant. Biores Technol 102:11212-11217

Deka H, Deka S, Baruah C, Das J, Hoque S, Sarma N (2011b) Vermicomposting of distillation waste of citronella plant (Cymbopogon winterianus Jowitt.) employing Eudrilus eugeniae. Biores Technol 102(13):6944-6950

Dhanam S (2009) Effect of dairy effluent on seed germination, seedling growth and biochemical parameter in Paddy. Bot Res Int 2(2):61-63

Dominguez J, Edwards C (1997) Effects of stocking rate and moisture content on the growth and maturation of Eisenia andrei (Oligochaeta) in pig manure. Soil Biol Biochem 29(3):743-746

Dominguez J, Edwards C (2004) Vermicomposting organic wastes: a review. Soil zoology for sustainable development in the 21st century, Cairo, pp 369-395

Dominguez J, Edwards CA, Dominguez J (2001) The biology and population dynamics of Eudrilus eugeniae (Kinberg)(Oligochaeta) in cattle waste solids. Pedobiologia 45(4):341-353

Edwards CA (2007) Earthworm ecology, 2nd edn. CRC Press, London

Edwards CA, Bohlen PJ (1996) Biology and ecology of earthworms, vol 3. Springer, Berlin

Elvira C, Sampedro L, Dominguez J, Mato S (1997) Vermicomposting of wastewater sludge from paper-pulp industry with nitrogen rich materials. Soil Biol Biochem 29(3-4):759-762

Elvira C, Sampedro L, Benitez E, Nogales R (1998) Vermicomposting of sludges from paper mill and dairy industries with Eisenia andrei: a pilot-scale study. Biores Technol 63(3):205-211

Gajalakshmi S, Ganesh PS, Abbasi S (2005) A highly cost-effective simplification in the design of fast-paced vermireactors based on epigeic earthworms. Biochem Eng J 22(2):111-116

Garg V, Kaushik P (2005) Vermistabilization of textile mill sludge spiked with poultry droppings by an epigeic earthworm Eisenia foetida. Biores Technol 96(9):1063-1071

Garg P, Gupta A, Satya S (2006) Vermicomposting of different types of waste using Eisenia foetida: a comparative study. Biores Technol 97(3):391-395

Hansen SB, Olsen SI, Ujang Z (2012) Greenhouse gas reductions through enhanced use of residues in the life cycle of Malaysian palm oil derived biodiesel. Biores Technol 104:358-366

Jain K, Singh J, Gupta S (2003) Development of a modified vermireactor for efficient vermicomposting: a laboratory study. Biores Technol 90(3):335-337

Kaplan DL, Hartenstein R, Neuhauser EF, Malecki MR (1980) Physicochemical requirements in the environment of the earthworm (Eisenia foetida). Soil Biol Biochem 12(4):347-352

Kaushik P, Garg VK (2003) Vermicomposting of mixed solid textile mill sludge and cow dung with the epigeic earthworm Eisenia foetida. Biores Technol 90(3):311-316

Krishnan Y, Bong CPC, Azman NF, Zakaria Z, Abdullah N, Ho CS, Lee CT, Hansen SB, Hara H (2016) Co-composting of palm empty fruit bunch and palm oil mill effluent: microbial diversity and potential mitigation of greenhouse gas emission. J Clean Prod 146:94-100

Kuroda K, Keno Y, Nakatani N, Otsuka K (2013) An integrated feasibility study of an anaerobic digestion plant using marine biomass and food waste. In: the twenty-third international offshore and polar engineering conference. International Society of Offshore and Polar Engineers

Lam MK, Lee KT (2011) Renewable and sustainable bioenergies production from palm oil mill effluent (POME): win-win strategies toward better environmental protection. Biotechnol Adv 29(1):124-141
Lee K (1992) Some trends and opportunities in earthworm research or: darwin's children-the future of our discipline. Soil Biol Biochem 24(12):1765-1771

Lim Siong H, Baharuddin Azhari Samsu, Ahmad Mohd Najib, Umi Kalsom Md, Shah Nor' Aini, Rahman Abdl, Abd-Aziz Suraini, Hassan Mohd Ali, Shirai Y (2009) Physichochemical changes in windrow co-composting process of oil palm mesocarp fiber and palm oil mill effluent anaerobic sludge. Aust J Basic Appl Sci 3(3):2809-2816

Lim SH, Baharuddin Azhari Samsu, Ahmad Mohd Najib, Umi Kalsom Md, Shah Nor' Aini, Rahman Abdl, Abd-Aziz Suraini, Hassan Mohd Ali, Shirai Y (2009) Physichochemical changes in windrow co-composting process of oil palm mesocarp fiber and palm oil mill effluent anaerobic sludge. Aust J Basic Appl Sci 3(3):2809-2816

Macci C, Masciandaro G, Ceccanti B (2009) Vermicomposting of olive oil mill wastewaters. Waste Manage Res 28(8):738

Madaki YS, Seng L (2013) Pollution control: how feasible is zero discharge concepts in Malaysia palm oil mills. Am J Eng Res 2:239-252

Mathur UB, Verma LK, Srivastava JN (2006) Effects of vermicomposting on microbiological flora of infected biomedical waste. J ISHWM 5(1):21-26

Mekki A, Dhouib A, Sayadi S (2013) Review: effects of olive mill wastewater application on soil properties and plants growth. Int J Recycl Org Waste Agric 2(1):1-7

Molina MJ, Soriano MD, Ingelmo F, Llinares J (2013) Stabilisation of sewage sludge and vinasse bio-wastes by vermicomposting with rabbit manure using Eisenia fetida. Biores Technol 137:88-97

Morais F, Queda C (2003) Study of storage influence on evolution of stability and maturity properties of MSW composts. In: Proceedings of the fourth International Conference of ORBIT association on Biological Processing of Organics: Advances for a sustainable Society Part II, Perth, Australia

MPOB (2014) Malaysian palm oil statistics 2013. Malaysian Palm Oil Board, Ministry of Plantation Industries and Commodities, Malaysia

Nogales R, Cifuentes C, Benitez E (2005) Vermicomposting of winery wastes: a laboratory study. J Environ Sci Health Part B 40(4):659-673

Nogales R, Saavedra M, Benitez E (2008) Recycling of wet olive cake"alperujo" through treatment with fungi and subsequent vermicomposting. Fresenius Environ Bull 17(11A):1822-1827

Ogunwenmo KO, Oyelana OA, Ibidunmoye O, Anyasor G, Ogunnowo AA (2010) Effects of brewery, textile and paint effluent on seed germination of leafy vegetables-amaranthus hybridus and celosia argentea (Amaranthaceae). J Biol Sci 10(2):151-156

Okwute L, Isu N (2007) The environmental impact of palm oil mill effluent (pome) on some physico-chemical parameters and total aerobic bioload of soil at a dump site in Anyigba, Kogi State, Nigeria. Afr J Agric Res 2(12):656-662

Raphael K, Velmourougane K (2011) Chemical and microbiological changes during vermicomposting of coffee pulp using exotic (Eudrilus eugeniae) and native earthworm (Perionyx ceylanesis) species. Biodegradation 22(3):497-507

Rupani PF, Singh RP, Ibrahim MH, Esa N (2010) Review of current palm oil mill effluent (POME) treatment methods: vermicomposting as a sustainable practice. World Appl Sci J 10(10):1190-1201

Salètes S, Siregar FA, Caliman J-P, Liwang T (2004) Ligno-cellulose composting: case study on monitoring oil palm residuals. Compost Sci Util 12(4):372-382

Sangwan P, Kaushik C, Garg V (2008) Vermiconversion of industrial sludge for recycling the nutrients. Biores Technol 99(18):8699-8704

Satisha G, Devarajan L (2007) Effect of amendments on windrow composting of sugar industry pressmud. Waste Manage 27(9):1083-1091 
Senapati BK, Dash MC, Rane AK, Panda BK (1980) Observation of the effect of earthworm in decomposition process in soil under laboratory conditions. Comp Physiol Ecol 5(3):140-142

Simard RR (1993) Ammonium acetate-extractable elements. In: Carter MR (ed) Soil sampling and methods of analysis. Lewis publishers, Boca Raton, London, pp 39-42

Suthar S (2009) Vermicomposting of vegetable-market solid waste using Eisenia fetida: impact of bulking material on earthworm growth and decomposition rate. Ecol Eng 35(5):914-920

Tripathi G, Bhardwaj P (2004) comparative studies on biomass production, life cycle and composting efficiency of Eisenia foetida (Savigny) and Lampito mauittii (Kinberg). Bioresource Technology 92:275-283
Yadav A, Garg V (2009) Feasibility of nutrient recovery from industrial sludge by vermicomposting technology. J Hazard Mater 168(1):262-268

Yadav KD, Tare V, Ahammed MM (2010) Vermicomposting of source-separated human faeces for nutrient recycling. Waste Manage 30(1):50-56

Yahya A, Sye CP, Ishola TA, Suryanto H (2010) Effect of adding palm oil mill decanter cake slurry with regular turning operation on the composting process and quality of compost from oil palm empty fruit bunches. Biores Technol 101(22):8736-8741

Zaller JG (2006) Foliar spraying of vermicornpost extracts: Effects on fruit quality and indications of lateblight suppression of fieldgrown tomatoes. Biol agric hortic 24(2):165-180 